\title{
Research of Tourism and Cultural Marketing Operation Model
}

\author{
Jinghui $\mathrm{Qu}^{1, \mathrm{a}}$ * \\ ${ }^{1}$ School of Management, Liaoning Institute of Science and Technology, Benxi, Liaoning 117004, \\ China \\ qujinghui_bx@163.com
}

Keywords: Culture; Tourism and cultural marketing; Mode of operation

\begin{abstract}
In modern society, the rapid development of materials, people pay attention to the material from the previous life now began to pursue the spirit of enjoyment and personal experience. In recent years, the tourism industry we have the emergence of new competitive situation, formed a product personal, professional and boutique into a target pattern. Therefore, the pursuit of cultural heritage tourism has become the mainstream thinking of today's society. Based on the conclusions of tourism and cultural marketing, the future development of tourism marketing and cultural tourism products combine propose new marketing approach for future tourism development.
\end{abstract}

\section{Introduction}

Tourism and cultural marketing specifically referring to, in order to improve the quality of tourism products and value-added services, cultural and tourism resources will design the concept together, under the current market demand for the cultural background of sublime pursuit, tourism resources and effective capital market the combined marketing. Not only tourists but also the pursuit of beauty in the pursuit of cultural needs, in pursuit of the tourism product in the process of cultural values and cultural tourism marketing, the perfect combination to achieve the fundamental purpose of tourism and cultural marketing. The key tourism and cultural marketing is different from other marketing methods that tourists in the tourism process in pursuit of tourism and cultural beauty in this pursuit fundamentally achieve resistance to other cultures, "three" culture. Meanwhile, unyielding pursuit also allows tourists aware of cultural tourism consumption process, hedonism and extravagant doctrine is a misunderstanding tourism and cultural consumption.

Spiritual and cultural marketing: this type of marketing, is the process of consumer travel in the ideological and moral values and cultural tourism throughout the process, tourists enjoy traveling in the process, but also raise the spiritual realm. Entertainment Cultural Marketing: In today's highly competitive society, people long in a very stressful life. Travel, it would be the main way people relax and entertainment. Today's society, sports and entertainment stars can often cause a very big interest in sporting events and they appear in the cultural arts activities, can often lead to cultural tourism marketing behavior. Knowledge Cultural Marketing: In order to give consumers a very rich self-expression, self-realization and to meet the needs of consumers in the travel process, content and cultural knowledge can be combined tourism products. It is also intended direction of travel of product development. From the point of view of long-term development of tourism, cultural marketing knowledge has its own unique way, we can improve the quality of citizens, contribute to a cultural construction in China.

Emotions Marketing: human development, emotions are running through them important cultural way, through which people can play the role of spiritual communication. Culture Fashion Marketing: marketing fashion culture means combining hot topics of social mentality of today's society and the development of a combination of tourism and cultural tourism marketing, this type of marketing can create a fashion culture. Of course, this type of marketing is also a short variable. Aesthetic Cultural Marketing: Aesthetic Culture marketing is to marketing activities and aesthetic style in literature, art, painting together, discovered during my travels in the United States, to create beauty, to give consumers the United States and experience in the course of travel, thereby generating consumption behavior. 


\section{Tourism and Cultural Marketing Mode of Operation}

Culture Packaging and product design. Cultural mode of operation and product packaging design combined refers to the tourist destinations on the basis of the original features, combined with cultural heritage, culture-oriented concept, in order to produce travel behavior cultural appeal and rich culture idea. In this mode of operation under travel behavior, it can greatly satisfy consumer culture psychology. In this mode of operation, which runs through the cultural ideas should, in order to improve the cultural quality of the product, and the nation's modern cultural awareness and health into which can increase the added value of tourism products, improve the cultural experience of consumers. Specific performance management system was shown in Fig. 1.

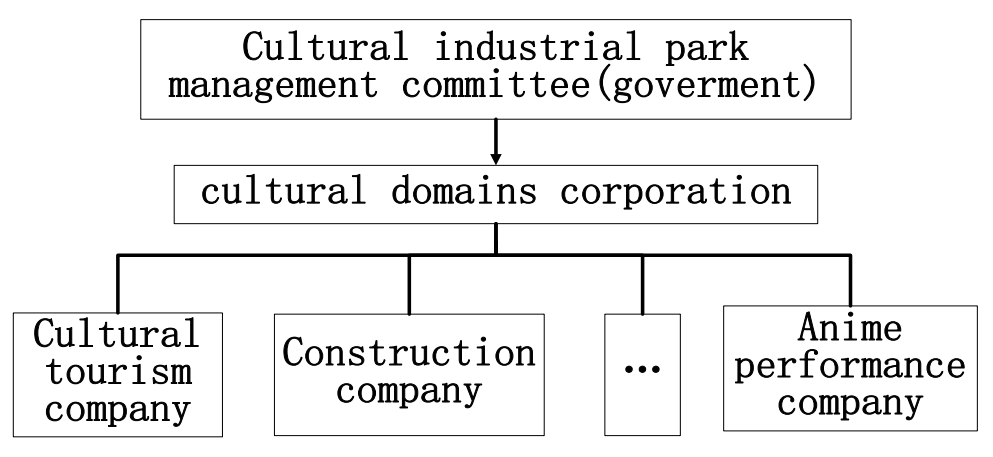

Figure 1. Specific performance management system

Marketing is the core elements of cultural tourism product marketing, product marketing, including production, design, packaging, and other aspects of modeling. Which is the basis of cultural marketing package of cultural attractions, should the product design, product design and product of rational distribution and other aspects of a comprehensive analysis of culture marketing. Marketing strategies and the background to fully understand the cultural tourism attractions and services personnel, a foreign country or regional ethnic characteristics fully reflected in the cultural products packaging. Cultural differences will use clever fusion of traditional culture and a new era of cultural features together, complement each other.

For multi-level within the range of economic, marketing communications play an important role. Cultural mode of transmission times, innovation, cultural marketing is a modernization of its mode of transmission, through cultural promotion and advertising and other means of cultural behavior as marketing communications systems, so it is a system communication behavior, where visitors satisfaction is a standard assessment. Cultural promotions in the short-term stimulus tool enables the low brand loyalty of visitors in a short time to purchase travel services and products, the purchase amount is generally relatively large. Due to the low brand loyalty, gifts and discounts to its visitors particularly concerned. This marketing approach during the run, determined to deal with the target, select the program to confirm the implementation of layout, control methods, and the results of each program selection to assess summary timely; cultural advertising in the marketing process primacy is to identify the target, the goal-setting process in response locate their target markets be evaluated to determine its marketing combinations. The key is to make tourists choose tourist products in the process of excitement targeted. Therefore, the advertising should focus on cultural tourism tourist's product characteristics, in the ad for product and company names are the focus of proposed target population.

Cultural experience and tourism brand. Experience tourism is a way more tourism, which means tourists in the tourism process, experience, and tourism activities through personal experience of differences, so that relatively strong psychological experience to meet tourism target tourists. Big psychological difference is due to different countries, experience, gender, region, education and national tourists choose to travel different angles, different travel routes, from different aspects and spiritual level, to meet the needs of a variety of tourist visitors travel experience activities. Tourism brand building process, experience tourism plays an important role. Brand building, tourism, culture 
has been flooded in the process of building them; comprehensive display of the entire process of cultural tourism brand is created; such cultural tourism and cultural content and enabling more brand more cohesiveness; culture can enhance the brand image, enhance the brand competitiveness. Therefore, the brand with cultural homogeneity is proportional to the degree of tourism products. Thus, competition is corporate culture brand competition the key. Tourism and cultural industry park in accordance with the functions of the government and market functional shift in the relationship to go through the initial stage of the government-led, government-enterprise co-existence and maturity of the market-led transition process, the paper market as a function of the abscissa, ordinate government functions constructed tourism and cultural industry park two functions effect relationship graph (Fig. 2).

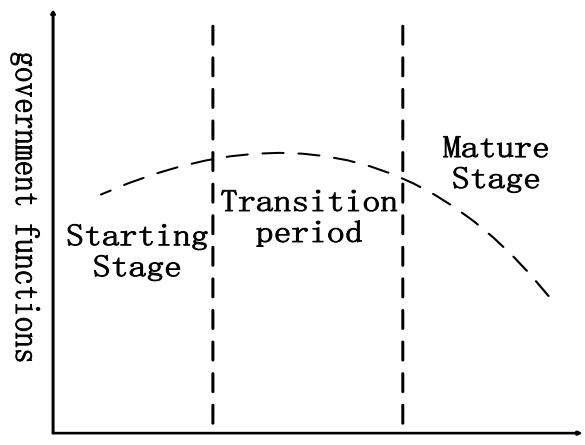

Figure 2. Government functions constructed tourism and cultural industry park two functions effect relationship graph

\section{Cultural Marketing}

Traditional marketing concept is basically a tangible product-centric, sales staff is designed to allow consumers to understand the convenience and economic practicality of the product and quickly converted into purchases, in order to achieve sales, as the market and consumer products What is the connection values and the number of products in the value of the new cohesion factor, they are rarely consciously consider cultural marketing is consciously through discovery, or create some kind of culture core values to achieve business objectives (economic, social, a marketing culture), that is in the sales process to fully express the value orientation of consumers, resonate, and ultimately achieve sales success. We can say that cultural marketing is to analyze culture as the basis, to meet consumer culture and emotional needs for the purpose of building the new corporate culture value chain; the product homogeneity of today, the new cultural marketing, to some extent, has become the first marketing of enterprises.

Evaluation Criteria cultural marketing is tourists' satisfaction, because culture is spread marketing communications system behavior of corporate culture, corporate values is the core of its spread, and therefore not to evaluate the communication behavior of individual product sales or services is reached or not the main criteria. That evaluation is not focused on the vision of a specific product or service, but tourists who, on the attitude of tourists, so the products, services and overall image for enterprises to provide tourists are satisfied culture is the evaluation of marketing communications quality standards, specific to the indicator is the tourists' satisfaction. The structure and level of cultural marketing was shown in Fig. 3.

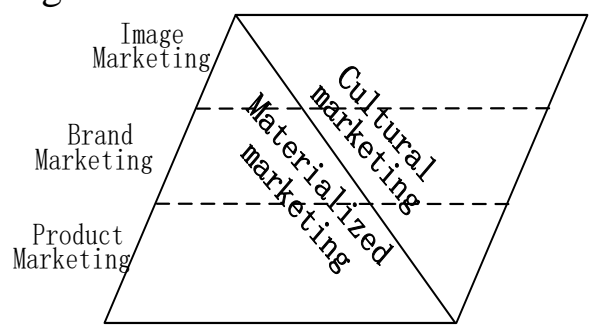

Figure 3. The structure and level of cultural marketing 
The fundamental goal is to achieve tourism and cultural marketing of tourism products and cultural value of cultural tourists meet, and cultural experience is the only way to achieve both maximize cultural value, satisfaction and experience within the cultural triangle formed corresponding to the cultural tourism internal frame cultural marketing, cultural marketing that is the essence of travel in from the outer to the inner triangle advancing the process, reflecting the operation of advanced marketing and cultural tourism, a deepening of the process: the first step is the product of the cultural package and design, the cultural value of the product; the second step adequate cultural communication and promotional operations to meet the cultural needs, both on the basis of the finalization of the perfect, unique cultural experiences under the concept of big brands, ultimately the core concept of tourism and cultural marketing. The basic framework for the marketing of tourism and cultural summarized as shown below:

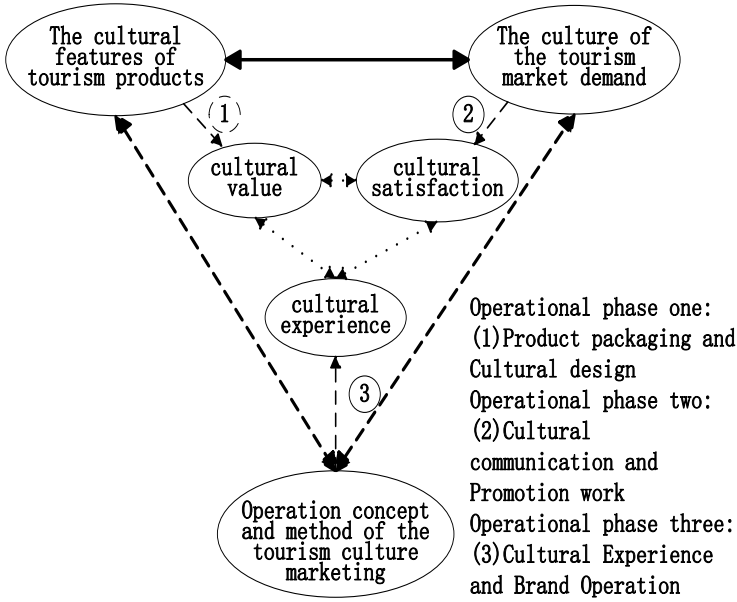

Figure 4. The basic framework for the marketing of tourism and cultural

\section{Conclusions}

The park speeds updates of products to enhance the level of Service Park. In the first two periods, to establish a clear idea of the park and make the environment optimization, implementation planning ahead and open channels of investment and financing diversified financing model to provide financial support for the construction of the park, according to the management of the park the actual situation the most favorable management methods, the use of multi-channel marketing and brand building parks do maintenance work. In the park maturity, the maximum weakening of government functions, service-oriented government, the enterprise market to maximize the operational functions of strengthening the management of enterprises as the main body of the park, in the meantime, the park constantly improve the industrial chain to explore out of the park, the park output superior products and intellectual resources.

\section{Acknowledgement}

This work is supported by the Social Sciences Fund Project of Liaoning in 2014 Research on Countermeasures of Liaoning County Area's Cultural Industry Development-Taking Huanren Manchu Autonomous County in Benxi for Example. Project number: L14BWJ007.

\section{References}

[1] Getz D. Event tourism: concepts, international case studies, and research [M]. Cognizant Communication Corporation, 2013. 
[2] Juan Z. On Translating Chinese Internet Buzzwords into English from the Perspective of Skopos Theory: Taking the Example of 2012 Chinese Internet Buzzwords [J]. Journal of Hubei Engineering University, 2013, 2: 017.

[3] Chen H. Research on Literary Translation Capability and the Construction of Training Mode[C]//2015 International Conference on Education Technology and Economic Management. Atlantis Press, 2015.

[4] Olson E M, Duruy R, Cooper C, et al. Strategy, structure, and culture within the English Premier League: an examination of large clubs [J]. Sport, Business and Management: An International Journal, 2016, 6(1).

[5] Zhang Z. Chinese and Canadian teachers implement a hybrid Sino-Canadian curriculum: A multiliteracies perspective [J]. Teaching and Teacher Education, 2015, 48: 106-116.

[6] Underwood P R. Teacher beliefs and intentions regarding the instruction of English grammar under national curriculum reforms: A Theory of Planned Behaviors perspective [J]. Teaching and Teacher education, 2012, 28(6): 911-925.

[7] Law R, Buhl's D, Cobanoglu C. Progress on information and communication technologies in hospitality and tourism [J]. International Journal of Contemporary Hospitality Management, 2014, 26(5): 727-750.

[8] Al-Issa A S M. Making a Case for New Directions in English Language Teaching Research at an Omani University: A Critical Qualitative Content Analysis Report [J]. The Qualitative Report, 2015, 20(5): 560 .

[9] Liu D, Li L. Analysis of the science development of the PST-CCE in applied undergraduate colleges and universities [J]. 2015.

[10]El-Gohary H. Factors affecting E-Marketing adoption and implementation in tourism firms: An empirical investigation of Egyptian small tourism organizations' [J]. Tourism Management, 2012, 33(5): 1256-1269. 